\title{
Do Different Disorders in Cell Cycle Regulation Account for Different Biological Behavior of Urothelial and Sinonasal Inverted Papillomas?
}

\author{
S. Gunia ${ }^{\text {a }} \quad$ F. Fritzsche ${ }^{c}$ M. May ${ }^{d} \quad$ D. Liebe ${ }^{\text {b }} \quad$ S. Koch $^{\text {a }}$ \\ a Institute of Pathology and ${ }^{b}$ Department of Otorhinolaryngology, HELIOS Klinikum Bad Saarow, Charité University \\ Medicine Teaching Hospital, Bad Saarow, ' Institute of Pathology, Charité University Medicine Berlin, Berlin, and \\ dDepartment of Urology, Carl Thiem Hospital Cottbus, Charité University Medicine Teaching Hospital, Cottbus, \\ Germany
}

\section{Key Words}

Inverted papilloma $\cdot$ Sinonasal mucosa $\cdot$ Urothelium $\cdot$

Cell cycle regulation - Tumor suppressor genes •

Immunohistochemistry

\begin{abstract}
Objective: It was the aim of this study to assess the expression of selected cell cycle regulation genes in urothelial and sinonasal inverted papillomas (IP). Methods: Archived surgically resected specimens from 18 urothelial and 19 sinonasal IP were studied immunohistochemically for p16, p53, cyclin D1 and Ki67. Staining results were semiquantified and compared between IP and adjacent control mucosa (CM). Results: p53 expression did not differ between sinonasal and urothelial IP. Although there was a trend of higher p53 expression in IP compared with the adjacent CM in sinonasal and urothelial specimens, this trend failed to be statistically significant. p16 expression was significantly higher in urothelial IP and CM in comparison with their sinonasal counterparts, but did not differ significantly between IP and its adjacent CM either in urothelial or sinonasal specimens. There were no significant differences in the mean scores for cyclin D1 or Ki67. Conclusion: The changes in p53 expression seen in both types of IP compared with adjacent CM suggest that sinonasal and urothelial IP may share some common ground in terms of their evolution. Although p16 appears not to be directly involved in the
\end{abstract}

\section{KARGER}

Fax +4161306 1234

E-Mail karger@karger.ch

www.karger.com
(C) 2008 S. Karger AG, Basel

1015-2008/08/0751-0034\$24.50/0

Accessible online at:

www.karger.com/pat development of sinonasal or urothelial IP, the differing recurrence patterns of sinonasal versus urothelial IP may be attributable in part to different p16 expression.

Copyright $\odot 2008$ S. Karger AG, Basel

\section{Introduction}

Urothelial and sinonasal inverted papillomas (IP) are rare benign ectodermal proliferations. Variation in recurrence might be caused by a combination of biological characteristics of the tumors coupled with variations in the surgical technique used for their resection [1]. Califano et al. [2] have shown that the tumorigenic characteristic of IP occurs due to monoclonal expansion of IP cells, but the actual trigger(s) that ultimately leads to tumor development and recurrence is still unknown.

Cell cycle checkpoints ensure the integrity of the genome and the fidelity of chromosome separation through ordered execution of cell cycle events. A breakdown in the regulation of the cell cycle can lead to uncontrolled growth and contribute to tumor formation. The $\mathrm{pRb}$ (pRb/p16/cyclin D1) and p53 (p14/mdm2/p53) pathways are the 2 main cell cycle control pathways frequently targeted in tumorigenesis [3-6].

This study was undertaken to comparatively investigate the expression of a panel of selected genes involved 
in cell cycle regulation by means of immunohistochemistry. Therefore, p53, p16 and cyclin D1 were chosen to be comparatively investigated in our study because these markers play a pivotal role in cell cycle control $[7,8]$. Additionally, Ki67 staining index (Ki67SI) was investigated in order to comparatively assess proliferative activity.

\section{Materials and Methods}

\section{Specimen Selection}

Retrospective computerized database analysis was performed in order to identify all patients with sinonasal and urothelial IP who underwent endoscopic surgery at the Department of Otorhinolaryngology, HELIOS Klinikum Bad Saarow (the former HUMAINE Klinikum Bad Saarow), between 1992 and 2001 (for sampling of sinonasal IP), and at the Department of Urology, HELIOS Klinikum Bad Saarow (the former HUMAINE Klinikum Bad Saarow), between 1991 and 2000 (for sampling of urothelial IP). Subsequently, this study was conducted upon archived surgical material comprising 18 urothelial IP (14 male and 4 female patients; mean age 55.6 years, range 32-63) and upon 19 sinonasal IP. The 19 sinonasal IP investigated were surgically resected (i.e. not merely intranasal biopsied) from a total of 11 patients ( 6 male and 5 female patients; mean age 48.2 years, range $33-78)$, of whom 8 (72.7\%) experienced 1 recurrence during follow-up comprising at least 5 years after surgery. Thus, 11 primary and 8 recurrent sinonasal IP were investigated.

Nonpapillomatous urothelial and sinonasal control mucosa (CM) was available in all cases (fig. 1,2). Pertinent medical information and demographics were retrospectively obtained by chart review.

The following criteria of exclusion were defined for both groups: exophytic growth pattern, nasal polyposis among the specimens with sinonasal IP, severe crush artifacts, dysplasia, koilocytosis, synchronous or metachronous malignant transformation during follow-up, and a history of smoking. The latter criterion was included because smoking has been reported to be etiologically associated with sinonasal IP $[9,10]$.

All patients diagnosed with urothelial IP were free of recurrence or progression during regular postsurgical cystoscopic follow-up comprising at least 5 years.

Surgical resection of sinonasal IP aimed at complete removal of all diseased mucosa which was clinically achieved in all cases. Recurrent sinonasal IP were situated either at the same anatomical location from which the antecedent IP have been removed before, or very close to this area. The mean time taken to develop recurrence was 21.8 months (range 13-49).

The final number of patients included in this study was established after excluding cases with insufficient documentation or those cases without meticulous follow-up comprising a period of at least 5 years after surgery.

\section{Conventional Staining}

Conventional hematoxylin and eosin $(\mathrm{H} \& \mathrm{E})$ staining was performed in all cases to establish the diagnoses and in order to rule out criteria of exclusion listed above.
Sinonasal IP included in this study consisted of ramifying cords and columns of cells invaginating into the underlying stroma from the covering surface epithelium and were lined by columnar (respiratory) and/or transitional (cuboidal) epithelium. Squamous epithelium was not present. Neither cytologic atypia nor koilocytosis was conventionally seen in any of the specimens studied.

\section{Immunohistochemistry}

Formalin-fixed paraffin-embedded archived surgically resected specimens were used for immunohistochemistry. Sequential tissue sections were cut using a microtome set at $5 \mu \mathrm{m}$. Sections were deparaffinized with graded alcohols and xylene. Antigen demasking was achieved by heat retrieval $\left(100^{\circ} \mathrm{C}\right)$ in $0.01 \mathrm{M}$ citrate buffer for $30 \mathrm{~min}$, automatically performed by Bond ${ }^{\mathrm{TM}}$ system (Visionbiosystems, Australia). The following primary antibodies were used: anti-p53 (monoclonal, dilution 1:300; DAKO, Hamburg, Germany), anti-cyclin D1 (monoclonal, dilution 1:20; Novocastra, NewCastle, UK), MiB1 (monoclonal, dilution 1:50; Novocastra) and anti-p16 (monoclonal, dilution 1:20; NeoMarkers, Fremont, Calif., USA). Primary antibodies were incubated at room temperature for $1 \mathrm{~h}$.

Subsequently, sections were washed with PBS and incubated with rabbit anti-mouse IgG 1:50, and following that, with mouse peroxidase-antiperoxidase conjugate 1:200. The enzymatic reaction was developed in a freshly prepared solution of diaminobenzidine ( $0.5 \mathrm{mg} / \mathrm{ml}$; Sigma, Deisenhofen, Germany) and 0.01\% hydrogen peroxide in water.

Except for p16, all immunohistochemical stainings were nucleus specific without any affinity for cytoplasm. In contrast, p16 showed nuclear and cytoplasmic staining (fig. 1, 2).

In all cases, negative staining controls were prepared for all primary antibodies used by omitting the first-layer antibody and processing the specimens exactly as described.

\section{Semiquantification of Immunostaining}

Except for p16, a positive immunostain was defined as distinct intranuclear granular staining. Concerning the expression of p16, intranuclear and cytoplasmic staining was considered for semiquantification as described elsewhere [11-13].

In all cases, immunoreactivity was recorded separately for IP and for its adjacent nonpapillomatous CM, respectively.

Semiquantification was performed by randomly selecting a total of 10 high-powered fields ( $40 \times$ magnification) from each specimen in order to avoid any sampling errors due to possible nonhomogeneous distribution of the markers investigated within the tumor tissue. Briefly, staining for the markers p53, p16 and cyclin D1 was graded on a 4-point scale according to the approach recently published by Robinson et al. [14] in the following fashion: point $1,0-25 \%$ cells positive; point $2,26-50 \%$ cells positive; point $3,51-75 \%$ cells positive, and point $4,76-100 \%$ cells positive. In contrast, Ki67SI was expressed as per cent of positively stained nuclei in relation to the total number of tumor cell nuclei considered. Again, mean values were calculated from a total of 10 randomly chosen high-powered fields in order to avoid possible sampling errors.

Evaluation of immunohistochemistry was separately performed by 2 independent histopathologists (S.G. and F.F.) blinded with respect to the specimens. 
Fig. 1. IP of the urinary bladder. H\&E. $\times 4$. Inset: cytoplasmic and nuclear expression of p16. $\times 40$.
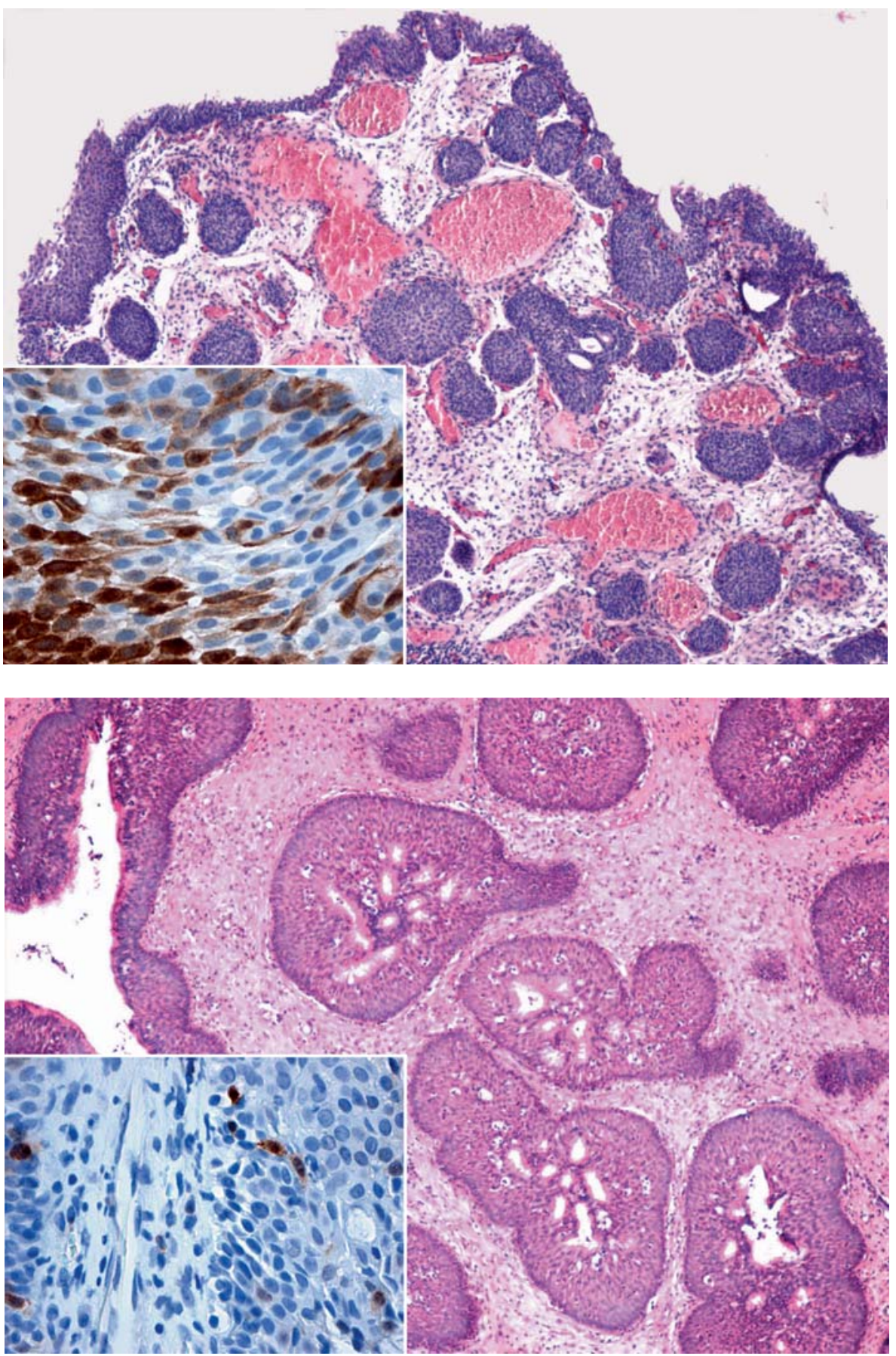
$\mathrm{H} \& \mathrm{E} . \times 4$. Inset: cytoplasmic and nuclear expression of $\mathrm{p} 16 . \times 40$.

\section{Results}

The nonparametric Mann-Whitney U test was used to statistically compare the independent parameters investigated in our study. $\mathrm{p}$ values $<0.05$ were considered significant. All calculations were performed using the statistical software package SPSS 13.0.
Gunia/Fritzsche/May/Liebe/Koch 
Table 1. Mean scores of p16 expression

\begin{tabular}{|c|c|c|c|c|}
\hline Specimen & $\begin{array}{l}\text { Mean score of } \\
\text { marker expression }\end{array}$ & $\begin{array}{l}95 \% \text { confidence } \\
\text { interval for the mean }\end{array}$ & $\begin{array}{l}\text { Standard } \\
\text { error }\end{array}$ & $\mathrm{p}$ value \\
\hline Urothelial CM $(n=18)$ & 1.13 & $0.77-1.49$ & 0.16 & \multirow[t]{2}{*}{0.915} \\
\hline Urothelial IP $(\mathrm{n}=18)$ & 1.16 & $0.83-1.48$ & 0.15 & \\
\hline Sinonasal CM $(\mathrm{n}=19)$ & 0.57 & $0.31-0.83$ & 0.12 & \multirow[t]{2}{*}{0.997} \\
\hline Sinonasal IP $(\mathrm{n}=19)$ & 0.57 & $0.31-0.83$ & 0.12 & \\
\hline Urothelial IP (n = 18) & 1.16 & $0.83-1.48$ & 0.15 & \multirow[t]{2}{*}{0.005} \\
\hline Sinonasal IP $(\mathrm{n}=19)$ & 0.57 & $0.31-0.83$ & 0.12 & \\
\hline Urothelial CM $(n=18)$ & 1.13 & $0.77-1.49$ & 0.16 & \multirow[t]{2}{*}{0.010} \\
\hline Sinonasal CM $(\mathrm{n}=19)$ & 0.57 & $0.31-0.83$ & 0.12 & \\
\hline Sinonasal CM, primary $(\mathrm{n}=11)$ & 0.64 & $0.28-1.00$ & 0.16 & \multirow[t]{2}{*}{0.477} \\
\hline Sinonasal CM, recurrence $(\mathrm{n}=8)$ & 0.46 & $0.01-0.91$ & 0.18 & \\
\hline Sinonasal IP, primary $(\mathrm{n}=11)$ & 0.64 & $0.26-1.03$ & 0.17 & \multirow[t]{2}{*}{0.489} \\
\hline Sinonasal IP, recurrence $(\mathrm{n}=8)$ & 0.46 & $0.03-0.89$ & 0.17 & \\
\hline
\end{tabular}

Table 2. Mean scores of p53 expression

\begin{tabular}{|c|c|c|c|c|}
\hline Specimen & $\begin{array}{l}\text { Mean score of } \\
\text { marker expression }\end{array}$ & $\begin{array}{l}95 \% \text { confidence } \\
\text { interval for the mean }\end{array}$ & $\begin{array}{l}\text { Standard } \\
\text { error }\end{array}$ & $\mathrm{p}$ value \\
\hline Urothelial CM $(\mathrm{n}=18)$ & 2.15 & $1.88-2.42$ & 0.13 & \multirow[t]{2}{*}{0.067} \\
\hline Urothelial IP $(\mathrm{n}=18)$ & 2.51 & $2.22-2.79$ & 0.13 & \\
\hline Sinonasal CM $(\mathrm{n}=19)$ & 2.22 & $1.98-2.46$ & 0.11 & \multirow[t]{2}{*}{0.138} \\
\hline Sinonasal IP $(n=19)$ & 2.49 & $2.20-2.77$ & 0.13 & \\
\hline Urothelial IP $(\mathrm{n}=18)$ & 2.51 & $2.22-2.79$ & 0.13 & \multirow[t]{2}{*}{0.921} \\
\hline Sinonasal IP $(\mathrm{n}=19)$ & 2.49 & $2.20-2.77$ & 0.13 & \\
\hline Urothelial CM $(\mathrm{n}=18)$ & 2.15 & $1.88-2.42$ & 0.13 & \multirow[t]{2}{*}{0.683} \\
\hline Sinonasal CM $(\mathrm{n}=19)$ & 2.22 & $1.98-2.46$ & 0.11 & \\
\hline Sinonasal CM, primary $(\mathrm{n}=11)$ & 2.21 & $1.85-2.57$ & 0.16 & \multirow[t]{2}{*}{0.942} \\
\hline Sinonasal CM, recurrence $(\mathrm{n}=8)$ & 2.23 & $1.85-2.61$ & 0.16 & \\
\hline Sinonasal IP, primary $(\mathrm{n}=11)$ & 2.48 & $2.14-2.81$ & 0.15 & \multirow[t]{2}{*}{0.943} \\
\hline Sinonasal IP, recurrence $(n=8)$ & 2.50 & $1.89-3.11$ & 0.25 & \\
\hline
\end{tabular}

mic expression of p16 did occur in all layers of the epithelium in urothelial and sinonasal IP and CM (fig. 1, 2), respectively.

The mean score of p16 expression was significantly higher in urothelial IP and CM compared with their sinonasal counterparts (urothelial vs. sinonasal IP, $\mathrm{p}=$ 0.005; urothelial vs. sinonasal CM, $\mathrm{p}=0.01$ ). There were no significant differences concerning p16 expression between IP and its adjacent CM either in urothelial (urothe- lial IP vs. urothelial CM, $\mathrm{p}=0.915)$ or sinonasal specimens (sinonasal IP vs. sinonasal CM, $\mathrm{p}=0.997$ ). Neither recurrent sinonasal IP nor its adjacent CM differed significantly in terms of p16 expression compared with the antecedent sinonasal IP or CM (antecedent vs. recurrent sinonasal IP, $\mathrm{p}=0.489$; sinonasal CM adjacent to antecedent sinonasal IP vs. sinonasal CM adjacent to recurrent sinonasal IP, $\mathrm{p}=0.477)$. 
Table 3. Mean scores of cyclin D1 expression

\begin{tabular}{|c|c|c|c|c|}
\hline Specimen & $\begin{array}{l}\text { Mean score of } \\
\text { marker expression }\end{array}$ & $\begin{array}{l}95 \% \text { confidence } \\
\text { interval for the mean }\end{array}$ & $\begin{array}{l}\text { Standard } \\
\text { error }\end{array}$ & $\mathrm{p}$ value \\
\hline Urothelial CM $(\mathrm{n}=18)$ & 1.80 & $1.63-1.98$ & 0.08 & \multirow[t]{2}{*}{0.171} \\
\hline Urothelial IP $(\mathrm{n}=18)$ & 1.96 & $1.80-2.13$ & 0.08 & \\
\hline Sinonasal CM $(\mathrm{n}=19)$ & 1.91 & $1.72-2.10$ & 0.09 & \multirow[t]{2}{*}{0.442} \\
\hline Sinonasal IP $(n=19)$ & 2.02 & $1.81-2.22$ & 0.10 & \\
\hline Urothelial IP $(\mathrm{n}=18)$ & 1.96 & $1.80-2.13$ & 0.08 & \multirow[t]{2}{*}{0.672} \\
\hline Sinonasal IP $(n=19)$ & 2.02 & $1.81-2.22$ & 0.10 & \\
\hline Urothelial CM $(\mathrm{n}=18)$ & 1.80 & $1.63-1.98$ & 0.08 & \multirow[t]{2}{*}{0.383} \\
\hline Sinonasal CM $(\mathrm{n}=19)$ & 1.91 & $1.72-2.10$ & 0.09 & \\
\hline Sinonasal CM, primary $(\mathrm{n}=11)$ & 1.94 & $1.65-2.24$ & 0.13 & \multirow[t]{2}{*}{0.728} \\
\hline Sinonasal CM, recurrence $(\mathrm{n}=8)$ & 1.87 & $1.58-2.17$ & 0.12 & \\
\hline Sinonasal IP, primary $(\mathrm{n}=11)$ & 2.02 & $1.72-2.33$ & 0.13 & \multirow[t]{2}{*}{0.934} \\
\hline Sinonasal IP, recurrence $(n=8)$ & 2.01 & $1.66-2.35$ & 0.15 & \\
\hline
\end{tabular}

There were no significant differences in the expression of cyclin D1 neither between IP and its adjacent CM (urothelial IP vs. urothelial CM, $\mathrm{p}=0.171$; sinonasal IP vs. sinonasal $\mathrm{CM}, \mathrm{p}=0.442$ ) nor between urothelial and sinonasal IP (uothelial vs. sinonasal IP, $\mathrm{p}=0.672$ ).

The mean level of p53 expression was higher in both types of IP in comparison with its adjacent CM, although this did not reach statistical significance (urothelial IP vs. urothelial CM, $\mathrm{p}=0.067$; sinonasal IP vs. sinonasal CM, $\mathrm{p}=0.138$ ). Expression of $\mathrm{p} 53$ did not differ significantly between urothelial and sinonasal IP (urothelial vs. sinonasal IP, $p=0.921)$. Staining results are summarized in tables $1-3$.

Nuclear Ki67 expression was recorded in less than 1\% of the basal cells in urothelial and in sinonasal IP and $\mathrm{CM}$. Thus, there were no significant differences between urothelial and sinonasal specimens concerning proliferative activity determined by means of Ki67 immunostaining.

\section{Discussion}

Urothelial and sinonasal IP are commonly acknowledged as ectodermal neoplasms, though this appellation remains controversial. This study aims to find reasonable explanations for the differing recurrence patterns between the 2 types of IP after surgical resection.

Hypothetically, different incidences of recurrences during follow-up might be attributable to incomplete sur- gical removal of sinonasal IP [15], possibly owing to the different surgical techniques applied for the resection of urothelial versus sinonasal IP (i.e. microinvasive endonasal endoscopic approach vs. transurethral resection). Although we cannot definitely exclude this possibility, we feel that other pathogenetic mechanisms are likely to be involved which would contribute to the profoundly different biological behaviors observed. It should be kept in mind that complete surgical removal of all sinonasal IP under study was achieved clinically; thus, residual neoplastic tissue appears very unlikely to be solely responsible for a recurrence rate of approximately $72.2 \%$. Since we failed to identify any significant differences in terms of proliferative activity assessed by means of Ki67SI between IP and CM in urothelial and sinonasal specimens, we focused on the comparative evaluation of a panel of selected candidates involved in cell cycle regulation.

Virtually all human tumors deregulate either the pRB or p53 pathway of cell cycle control, and sometimes, even both pathways simultaneously $[7,8]$. Thus, p16, cyclin D1 and $\mathrm{p} 53$ were the candidates chosen to be comparatively investigated in our study by means of immunohistochemistry.

The distribution pattern of these markers within the layers of the epithelium did not differ between IP and CM neither in urothelial nor in sinonasal specimens.

p53 represents a key gatekeeper that helps regulate DNA replication, cell proliferation and apoptosis [16]. Mutations in this gene occur in more than $50 \%$ of human cancers [17]. 
We found the mean level of p53 expression to be higher in urothelial and sinonasal IP compared with its adjacent $\mathrm{CM}$, indicating that this cell cycle regulation gene might be pathogenetically involved in the evolution of both types of IP. Thus, there may be some shared common ground in the evolution of both types of IP, although this hypothesis remains to be proven. It is thought that decreased apoptosis might allow for genetic alterations to be perpetuated, leading to tumor progression [2]. Although the observed differences in the mean p53 expression between urothelial and sinonasal IP and CM failed to be statistically significant in our study, it should be kept in mind that mutations of the p53 gene are not necessarily associated with immunopositivity for p53 [18], and thus, our results do not allow for drawing definite conclusions concerning alterations of the p53 gene in IP - an interesting target to be addressed in future studies.

The $\mathrm{pRb}$ (pRB/p16/cyclin D1) pathway comprises key components involved in the progression through the G1 phase of the mammalian cell cycle $[19,20]$. Cyclin D1, a member of this pathway, encodes the regulatory subunit of a holoenzyme that phosphorylates and inactivates the retinoblastoma protein and promotes progression through the G1-S phase of the cell cycle. Cyclin D1 can function as a transcriptional coregulator [21], but the most well-understood function of the D-type cyclins is to activate the G1 kinases, cdk4 and cdk6, and target the retinoblastoma gene product $(\mathrm{pRb})$ for phosphorylation and inactivation [22].

Amplification and/or overexpression of cyclin D1 plays a pivotal role in the development of a subset of human neoplastic proliferations [23], but did not appear to be directly involved in the development of urothelial or sinonasal IP in our study.

We failed to identify any significant differences in the mean expression of p53, cyclin D1 and Ki67SI between both types of IP. Therefore, according to our results, these proteins do not offer any reasonable explanation regarding the different biological behavior of both types of IP in terms of recurrence after surgical resection. However, this notion awaits confirmation by additional molecularbiological studies.

p16 is a bona fide tumor suppressor gene which blocks cell cycle progression by binding cdk $4 / 6$ and by antagonizing D-type cyclins. In particular, p16 blocks the G1- to S-phase progression of the cell cycle by promoting the inhibition of $\mathrm{pRb}$ phosphorylation and the formation of a pRb/E2F-repressive complex [24,25], ultimately leading to a state of cell cycle arrest resembling replicative senescence [26]. Interestingly, p16-deficient mice are prone to develop spontaneous tumors [27]. In this context, small homozygous deletions represent the major mechanism of p16 inactivation in various primary tumors while mutations are not commonly reported [28-31]. Moreover, aberrant methylation of $\mathrm{p} 16$ has been shown in a wide variety of human tumors [32].

Deregulation of p16 does not appear to be directly involved in the evolution of urothelial or sinonasal IP since its expression did not differ significantly between IP and its adjacent CM. However, we found a significantly higher expression of p16 in urothelial IP and CM in comparison with their sinonasal counterparts. This phenomenon might, by preventing the urothelium from cell cycle (re-)entry, contribute to the observed differences in terms of recurrent sinonasal IP which did not occur in urothelial IP during follow-up.

The puzzling question as to whether recurrences might have arisen either from the adjacent sinonasal CM or from small foci of clinically undetectable residual IP which might have been left behind during microinvasive surgery remains a subject of speculation. Since all sinonasal recurrences occurred either at the same anatomical location from which the antecedent IP has been resected before or at least very close to this area, both pathways are felt to be possible.

Following the assumption that p16 might be pathogenetically involved in the evolution of recurrent sinonasal IP, another phenomenon that merits emphasis is the question why 'only' $72.7 \%$ of the sinonasal IP under study developed recurrences during follow-up. One might speculate that the follow-up provided in our study might be too short, and thus, prolonged observation might reveal more sinonasal IP also to recur. A possible multi-step process involving other members of cell cycle control might also be suspected to be involved in the establishment of recurrent sinonasal IP. It should be noted that although p16 and cyclin D1 do not seem to be directly involved in the evolution of IP, their possible implication in those hypothetical multi-step mechanisms cannot be excluded. So far unknown hypothetical events might lead to monoclonal expansion accounting for the evolution of recurrent sinonasal IP [2]. However, the elucidation of these possible mechanisms is beyond the scope of this study and requires additional thorough studies. For example, although koilocytosis was defined as representing a criterion of exclusion in this work, the presence of human papilloma virus cannot be excluded by conventional H\&E staining alone [33]. Thus, further studies focusing on human papilloma virus status (e.g., by means of polymerase chain reaction and/or by hybridization tech- 
niques) should be conducted in order to contribute to a better understanding of the different biological behavior of urothelial and sinonasal IP. Especially, these studies should include a larger number of primary sinonasal IP in order to provide the basis for statistically comparing the cell cycle regulation proteins selected to be investigated in this study between primary sinonasal IP with and without recurrence during follow-up, because the limited number of primary sinonasal IP without recurrence during follow-up available in our study $(\mathrm{n}=3)$ was felt to be inappropriate for addressing this interesting target.

\section{Conclusion}

This study established a trend of higher p53 expression in urothelial and sinonasal IP compared with its adjacent $\mathrm{CM}$, suggesting that this cell cycle regulation gene might be pathogenetically involved in the development of both types of IP which might share some common ground in their early evolution. Furthermore, we detected a significantly higher expression of p16 in urothelial IP and CM in comparison with their sinonasal counterparts. In contrast, expression of p16 did not differ significantly between IP and its adjacent nonpapillomatous CM neither in urothelial nor in sinonasal specimens, suggesting that p16 might not directly be pathogenetically involved in the evolution of urothelial or sinonasal IP. However, by blocking cell cycle progression due to G1 arrest, this different expression might contribute to the different biological behaviors observed between the 2 types of IP in terms of recurrence after surgical resection.

\section{References}

1 Wormald PJ, Ooi E, van Hasselt CA, Nair S: Endoscopic removal of sinonasal inverted papilloma including endoscopic medial maxillectomy. Laryngoscope 2003;113:867873.

2 Califano J, Koch W, Sidransky D, Westra WH: Inverted sinonasal papilloma: a molecular genetic appraisal of its putative status as a precursor to squamous cell carcinoma. Am J Pathol 2000;156:333-337.

3 Giaccia AJ, Kastan MB: The complexity of p53 modulation: emerging patterns from divergent signals. Genes Dev 1998;12:29732983.

-4 Gan D, Macaluso M, Cinti C, Khalili K, Giordano A: How does a normal cell become a cancer cell ? J Exp Clin Cancer Res 2003;22: 509-516.

5 Sherr CJ, McCormick F: The RB and p53 pathways in cancer. Cancer Cell 2002;2:103112.

6 Macaluso M, Russo G, Cinti C, Bazan V, Gebbia N, Russo A: Ras family genes: an interesting link between cell cycle and cancer. J Cell Physiol 2002;192:125-130.

7 Yamasaki L: Role of the RB tumor suppressor in cancer. Cancer Treat Res 2003;115:209_ 239.

8 Stewart CL, Soria AM, Hamel PA: Integration of the pRB and p53 cell cycle control pathways. J Neurooncol 2001;51:183-204.
-9 Deitmer T, Wiener C: Is there an occupational etiology of inverted papilloma of the nose and sinuses? Acta Otolaryngol 1996;116: 762-765.

10 Barbieri PG, Tomenzoli D, Morassi L, Festa R, Fernicola C: Sino-nasal inverted papillomas and occupational etiology. G Ital Med Lav Ergon 2005;27:422-426.

11 Walts A, Lechago J, Bose S: p16 and Ki67 immunostaining is a useful adjunct in the assessment of biopsies for HPV-associated anal intraepithelial neoplasia. Am J Surg Pathol 2006;30:795-801.

12 Mihic-Probst D, Saremasiani P, Komminroth P, Heitz P: Immunostaining for the tumor suppressor gene $\mathrm{p} 16$ product is a useful marker to differentiate melanoma metastasis from lymph-node nevus. Virchows Arch 2003;443:745-751.

13 Salama M, Mahmood M, Qureshi H, Ma C, Zarbo R, Ormsby A: P16INK4a expression in actinic keratosis and Bowen's disease. Br J Dermatol 2003;149:1006-1012.

14 Robinson S, Tan LW, James C, Karakousis A, Wormald PJ: Do nasal polyps and inverted papilloma have similar disorders in cell cycle regulation? Am J Rhinol 2006;20:641-647.

15 Hyams VJ: Papillomas of the nasal cavity and paranasal sinuses: a clinicopathological study of 315 cases. Ann Otol Rhinol Laryngol 1971;80:192-206.

$\checkmark 16$ Lowe SW, Cepero E, Evan G: Intrinsic tumour suppression. Nature 2004;432:307315.

17 Vousden KH, Prives C: p53 and prognosis: new insights and further complexity. Cell 2005;120:7-10.
18 Xu L, Chen YT, Huvos AG, Zlotolow IM, Rettig WJ, Old LJ, Garin-Chesa P: Overexpression of $\mathrm{p} 53$ protein in squamous cell carcinomas of head and neck without apparent gene mutations. Diagn Mol Pathol 1994;3:83-92.

19 Stiegler P, Giordano A: The family of retinoblastoma proteins. Crit Rev Eukaryot Gene Expr 2001;11:59-76.

20 Frolov MV, Dyson NJ: Molecular mechanisms of E2F-dependent activation and pRbmediated repression. J Cell Sci 2004;117: 2173-2181.

21 Alao JP: The regulation of cyclin D1 degradation: roles in cancer development and the potential for therapeutic invention. Mol Cancer 2007;2:6-24.

22 Baker GL, Landis MW, Hinds PW: Multiple functions of D-type cyclins can antagonize pRb-mediated suppression of proliferation. Cell Cycle 2005;4:330-338.

23 Fu M, Wang C, Li Z, Sakamaki T, Pestell RG: Minireview: Cyclin D1: normal and abnormal functions. Endocrinology 2004;145: 5439-5447.

24 Zhang HS, Postigo AA, Dean DC: Active transcriptional repression by pRb-E2F complex mediates G1 arrest triggered by p16INK4a, TGFbeta, and contact inhibition. Cell 1999;97:53-61.

25 Serano M, Hannon GJ, Beach D: A new regulatory motif in cell-cycle control causing specific inhibition of cyclin D/CDK4. Nature 1993;366:704-707. 
26 Groth A, Weber JD, Willumsen BM, Sherr CJ, Roussel MF: Oncogenic Ras induces p19ARF and growth arrest in mouse embryo fibroblasts lacking p21Cip1 and p27Kip1 without activating cyclin D-dependent kinases. J Biol Chem 2000;275:27473-27480.

-27 Serano M, Lee HW, Chin L, Cordon-Cardo C, Beach D, DePinho RA: Role of the INK4a locus in tumor suppression and cell mortality. Cell 1996;85:27-37.

-28 Zhang Y, Xiong Y, Yarbrough WG: ARF promotes MDM2 degradation and stabilizes p53: ARF-INK4ka locus deletion impairs both the $\mathrm{Rb}$ and $\mathrm{p} 53$ tumor suppression pathways. Cell 1998;92:725-734.
29 Cairns P, Polascik TJ, Eby Y, Tokino K, Califano J, Merlo A, Mao L, Herath J, Jenkins R, Westra W: Frequency of homozygous deletion at p16/CDKN2 in primary human tumours. Nat Genet 1995;11:210-212.

30 Jen J, Harper JW, Bigner SH, Bigner DD, Papadopoulos N, Markowitz S, Wilson JK, Kinzler KW, Vogelstein B: Deletion of p16 and p15 genes in brain tumors. Cancer Res 1994;54:6353-6358.
31 Ohta M, Nagai H, Shimizu M, Rasio D, Berd D, Mastrangelo M, Singh AD, Shields JA, Shields CL, Croce CM: Rarity of somatic and germline mutations of the cyclin-dependent kinase 4 inhibitor gene, CDK4I, in melanoma. Cancer Res 1994;54:5269-5272.

32 Esteller M: Dormant hypermethylated tumour suppressor genes: questions and answers. J Pathol 2005;205:172-180.

33 Morse AR, Wickenden C, Byrne M, TaylorRobinson D, Smith J, Anderson MC, Smith C, Malcolm AD, Coleman DV: DNA hybridisation of cervical scrapes: comparison with cytological findings in Papanicolaou smears. J Clin Pathol 1988;41:296-299. 